\title{
Licenciamento ambiental em áreas cársticas no Brasil: uma análise sob a ótica dos Stakeholders
}

A avaliação de impactos ambientais, em virtude da instalação de obras ou empreendimentos efetivamente poluidores ou causadores de impactos ambientais negativos, é condição essencial para o licenciamento ambiental no Brasil. É considerada um valioso instrumento para gestão ambientalmente adequada do uso dos recursos naturais. Este instrumento se torna ainda mais relevante quando se trata do uso de ambientes extremamente frágeis e suscetíveis a impactos advindos de ações antrópicas. Neste sentido, destacam-se as áreas cársticas, consideradas parte do patrimônio espeleológico brasileiro, com uma gama de instrumentos que almejam sua proteção. $\mathrm{O}$ ambiente cárstico é um sistema ambiental bastante complexo com presença de diversos elementos da sociobiodiversidade, marcado paisagisticamente pela presença de cavernas e com importantes redes de drenagem subterrânea. Toda essa riqueza ambiental tornou obrigatória a realização de estudos e o licenciamento ambiental, diante da construção de empreendimentos em sua área de influência. Portanto, o objetivo desta pesquisa é analisar o entendimento, possíveis entraves e dificuldades no processo de licenciamento ambiental em áreas cársticas, considerando os instrumentos deste processo, bem como a atuação dos agentes de interesses sobre uso de recursos naturais, denominados na pesquisa de Stakeholders, que compõem os órgãos ambientais do licenciamento no Brasil. Partindo do recorte metodológico dos principais instrumentos do licenciamento ambiental, correlacionando com a visão dos Stakeholders sobre estes instrumentos e suas formas de aplicabilidade, os resultados apontam para a direção de que os Stakeholders conhecem os instrumentos do licenciamento ambiental no Brasil e não apontam grandes entraves mas reconhecem a necessidade de uma atuação mais sistêmica, conforme preconizam os próprios instrumentos normativos.

Palavras-chave: Gestão Ambiental; Empreendimentos; Impacto; Carste.

\section{Environmental licensing in karst areas in Brazil: an analysis from the perspective of Stakeholders}

\begin{abstract}
The assessment of environmental impacts, due to the installation of works or projects that effectively pollute or cause negative environmental impacts, is an essential condition for environmental licensing in Brazil. It is considered a valuable tool for environmentally sound management of the use of natural resources. This instrument becomes even more relevant when it comes to the use of extremely fragile environments and susceptible to impacts from anthropic actions. In this sense, karst areas stand out, considered part of the Brazilian speleological heritage, with a range of instruments that aim for their protection. The karstic environment is a very complex environmental system with the presence of several elements of sociobiodiversity, landscaped with caves and important underground drainage networks. All this environmental wealth has made it mandatory to carry out studies and environmental licensing, given the construction of enterprises in its area of ??influence. Therefore, the objective of this research is to analyze the understanding, possible obstacles and difficulties in the process of environmental licensing in karst areas, considering the instruments of this process, as well as the action of stakeholders about the use of natural resources, named in the Stakeholders survey, that make up the environmental licensing agencies in Brazil. Starting from the methodological outline of the main environmental licensing instruments, correlating with the Stakeholders' view on these instruments and their applicability, the results point to the direction that the Stakeholders know the environmental licensing instruments in Brazil and do not point to major obstacles. recognize the need for more systemic action, as advocated by the normative instruments themselves.
\end{abstract}

Keywords: Environmental management; Enterprises; Impact; Karst.

Topic: Planejamento, Gestão e Políticas Públicas Ambientais

Reviewed anonymously in the process of blind peer.

Elistênia da Fonsêca Bezerra Teles

Instituto Federal do Maranhão, Brasil

http://lattes.cnpq.br/0928195735539844

http://orcid.org/0000-0002-3889-5925

elisteniafonseca@gmail.com

Fernando de Morais (iD

Universidade Federal do Tocantins, Brasil

http://lattes.cnpq.br/2925654570470585

http://orcid.org/0000-0002-0311-3823

morais@uft.edu.br

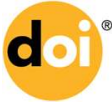

DOI: 10.6008/CBPC2179-6858.2018.006.0030
Received: 23/08/2018

Approved: 28/08/2018
Referencing this:

TELES, E. F. B.; MORAIS, F.. Licenciamento ambiental em áreas cársticas no Brasil: uma análise sob a ótica dos Stakeholders. Revista Ibero-Americana de Ciências Ambientais, v.9, n.6, p.321-332, 2018. DOI: http://doi.org/10.6008/CBPC2179-6858.2018.006.0030 


\section{INTRODUÇÃO}

As fortes pressões e o intenso crescimento dos movimentos sociais de cunho ambientalistas, iniciados no final dos anos de 1960 e início dos anos de 1970, impulsionaram a adoção de procedimentos de preocupação ambiental em várias partes do mundo. Um dos países precursores na determinação de dispositivos legais para a definição de objetivos e princípios de uma política ambiental, voltada para a gestão de obras causadoras de potencial poluição, foram os Estados Unidos, por meio de uma Lei Federal, denominada National Enviroment Policy Act - NEPA, aprovada em 1969 naquele país. Esta lei prevê que todos os empreendimentos com grande potencial de impacto ambiental procedessem, dentre outras obrigações, à identificação dos impactos ambientais, caracterização dos efeitos negativos e à definição de ações e meios para mitigação desses impactos sobre o ambiente.

No Brasil, o primeiro dispositivo legal associado à Avaliação de Impactos Ambientais - AIA, deu-se por meio da aprovação da Política Nacional de Meio Ambiente PNMA (Lei no 6938/1981), que trouxe o conceito de impacto ambiental e tornou obrigatória a realização de estudos ambientais para construção de obras ou empreendimentos potencialmente poluidores em território brasileiro. Mas foi somente em 1986 que ocorreu a regulamentação deste instrumento, através da resolução do Conselho Nacional de Meio Ambiente - CONAMA 001/86, posteriormente alterada pela resolução CONAMA 237/97. Foi esta resolução que determinou os passos para a execução de avaliações de impacto ambiental estabelecendo definições, responsabilidades, critérios e diretrizes para uso e implementação da AIA em âmbito nacional.

Para Bursztyn et al. (2012), a avaliação de impacto ambiental é um "instrumento de planejamento que permite associar as preocupações ambientais às estratégias do desenvolvimento social e econômico", permitindo inferir que se trata de uma ferramenta de gerenciamento ambiental. Os resultados deste processo de avaliação e mensuração dos impactos decorrentes da implantação de um empreendimento são apresentados no Estudo de Impacto Ambiental e o seu respectivo Relatório de Impacto Ambiental EIA/RIMA. Assim, estes são considerados produto final da AIA e sua definição legal é que se trata do "conjunto de estudos realizados por especialistas de diversas áreas, com dados técnicos detalhados sobre o empreendimento" (CONAMA, 1997).

O principal objetivo do EIA/RIMA é, portanto, garantir que os órgãos ambientais (IBAMA, órgãos estaduais e municipais) possam reconhecer e atestar a viabilidade socioambiental, bem como conceder a licença aos empreendimentos e garantir a aplicabilidade das medidas mitigadoras destas atividades. A apresentação do EIA/RIMA é condição sino quo non, dentro do processo de licenciamento ambiental, sem sua análise não há concessão da licença ambiental. O Licenciamento Ambiental é compreendido como sendo

(...) um procedimento administrativo pelo qual o órgão ambiental pode licenciar a localização, instalação, ampliação, modificação e operação de atividades e empreendimentos que se utilizam de algum recurso ambiental e que sejam considerados efetiva ou potencialmente poluidores ou daqueles que, sob qualquer forma, possam causar algum desgaste ou qualquer tipo de degradação ambiental, atendendo os requisitos legais exigidos. Este processo resulta, portanto, na emissão da licença ambiental.

Corrêa et al. (2012) apontam que, enquanto instrumento de gestão, o licenciamento "é atualmente um dos mais importantes dentro da política e da gestão ambiental. (...), por ser instrumento de gestão, é a 
instituição que realiza a interface entre os sistemas político, econômico, social, jurídico e ecológico". As licenças ambientais são emitidas considerando as três fases da atividade a ser licenciada: planejamento, instalação e operação.

De acordo com o art. 8 da resolução CONAMA 237/97 cabe ao poder público a emissão das seguintes licenças: Licença Prévia (LP): concedida na fase preliminar do planejamento da atividade ou na sua expansão, tem o objetivo de verificar a viabilidade do projeto e/ou localização de equipamento ou atividade, quanto aos aspectos de impacto e diretrizes de uso do solo (federal, estadual e municipal); Licença de Instalação (LI): autoriza o início da implantação da atividade ou instalação de qualquer equipamento, de acordo com o plano de controle ambiental e com base no projeto executivo das medidas mitigadoras dos impactos ambientais, estudadas na fase de LP.

Além desses, tem-se Licença de Operação (LO): autoriza o funcionamento do equipamento, atividade ou serviço, com base em vistoria, teste de operação ou qualquer meio técnico, verificado o funcionamento dos equipamentos de controle de poluição e dos sistemas de controle de degradação ambiental, estudados nas fases de LP e LI.

No contexto da conservação dos recursos naturais, e se apresentando como um instrumento protetivo, o licenciamento ambiental ganha mais importância quando se trata de gestão de ambiente e/ou ecossistemas mais frágeis e suscetíveis a impactos ambientais de cunho negativo. Cabe então exemplificar como símbolo da fragilidade ambiental: o sistema cárstico, compreendido como sendo, conforme Ribas et al. (2009),

(...) um ecossistema frágil e delicado, contendo, normalmente, além do corpo rochoso, conteúdo mineral e hídrico, fauna, flora, sítios arqueológicos e paleontológicos. Apresenta uma grande importância ambiental, cultural e econômica e um forte apelo turístico, face à beleza cênica dos espeleotemas, dos rios e lagos subterrâneos, das cachoeiras e dos vestígios históricos.

Desta forma, considerando a complexidade destes componentes, o mais adequado é caracterizá-lo como sendo um sistema ambiental, parte integrante do patrimônio espeleológico brasileiro com uma gama de instrumentos legislativos que almejam a sua proteção, incluindo o licenciamento ambiental de obras ou empreendimentos em sua área de influência direta ou indireta. Cavalcanti et al. (2013), acerca do patrimônio espeleológico brasileiro, explica que o mesmo

(...) está inserido em um cenário que exige respostas concretas advindas de políticas públicas integradas e que considerem efetivamente as variáveis sociais, econômicas e ambientais, a fim de que o estado de conservação do ambiente cárstico não seja desestruturado ou comprometido.

Figueiredo et al. (2010) direciona a discussão em torno da proteção do patrimônio espeleológico brasileiro como um ponto de conflito que envolve interesses individuais e distintos, uma vez que: "Proteger as cavernas como patrimônio natural único, sensível e peculiar ou obter recursos minerais para o desenvolvimento da sociedade contemporânea. Esse parece ser um dilema insolúvel".

Apontar estratégias para a exploração ambientalmente adequada do Patrimônio Espeleológico e da biodiversidade a ele associada, deve estar condicionada a existência de um conjunto de ações incluindo pesquisas realizadas com auxílio de políticas públicas, "que determinem formas eficientes de exploração 
sustentada e garantidora da manutenção do equilíbrio ecológico nestes ecossistemas (CAVALCANTI et al., 2012)", neste sentido, destaca-se o processo de licenciamento ambiental.

O licenciamento também garante que caso haja impactos oriundos da atividade ou empreendimento, estes possam ser mitigados através das medidas mitigadoras e/ou compensatórias. No que concerne à gestão de áreas cársticas, o LA garante que os órgãos ambientais possam monitorar as áreas de influência direta do empreendimento, com presença de cavidades em área do sistema cárstico.

Neste cerne de discussão é importante ressaltar que o licenciamento ambiental em áreas cársticas, depende não apenas do que é disposto nas resoluções CONAMA, mas também no que estabelece a Lei Complementar - LC 140/2011, que fixa normas para a cooperação entre a União, os Estados, o Distrito Federal e os Municípios nas ações administrativas decorrentes do exercício da competência comum relativas à proteção das paisagens naturais notáveis, à proteção do meio ambiente, ao combate à poluição em qualquer de suas formas e à preservação das florestas, da fauna e da flora; e altera a Lei no 6.938, de 31 de agosto de 1981

Ademais, há de se considerar a atuação dos agentes dos órgãos que atuam no processo de licenciamento ambiental destas áreas. Parte-se do pressuposto, que considerando o Carste em uma perspectiva sistêmica, o licenciamento destas áreas deve ser ação integrada e sistêmica, com a atuação dos órgãos que compõem a gestão destas áreas no Brasil.

De acordo com as normas ambientais brasileiras, o processo de licenciamento ambiental em áreas cársticas dependem basicamente da atuação de dois órgãos: O Instituto Brasileiro de Recursos Naturais Renováveis - IBAMA e do Centro Nacional de Pesquisa e Conservação de Cavernas - CECAV, autarquia do governo federal, integrante da composição do Instituto Chico Mendes de Conservação da Biodiversidade ICMBio. O primeiro responsável pela emissão da licença nas diversas fases do empreendimento e o segundo por dar suporte técnico no cumprimento de normas complementares.

Portanto, o objetivo central desta pesquisa é analisar o papel dos agentes que atuam sobre o processo de licenciamento ambiental, em áreas cársticas no Brasil, especialmente a atuação do IBAMA e do CECAV. O recorte metodológico perpassou pela identificação destes agentes, baseando-se nos instrumentos de gestão das áreas cársticas, especialmente o licenciamento ambiental, bem como na identificação de possíveis conflitos existentes deste processo.

\section{METODOLOGIA}

Para o estudo do processo de licenciamento ambiental em áreas cársticas no Brasil, esta pesquisa buscou aporte metodológico na 'Análise dos Stakeholders' - AS. Apesar de não possuir uma tradução literal de seu léxico a 'AS' pode ser traduzida para a língua portuguesa, como 'grupo de interesse'. Autores como Freeman (1984), Campbel (1997) e Rowley (1998), utilizam semanticamente o vocábulo para identificar grupos ou agentes que atuam direta ou indiretamente sobre um determinado ambiente.

Chevalier (2001) procurou definir um Stakeholder como "Qualquer pessoa, grupo ou organização, em diversos níveis (local, regional, nacional, internacional), que afeta ou é afetado pela dinâmica de 
funcionamento de um dado sistema de recursos naturais". Portanto, nesta pesquisa entende-se como Stakeholders, aquele órgão ou setor que atua sobre a gestão de áreas cársticas no Brasil e de forma específica com interesses no processo de licenciamento ambiental. Do ponto de vista operacional esta pesquisa baseouse na matriz de análise da atuação dos Stakeholders proposta por Grimbler et al. (1995), disposta no quadro 1. Assim, as diretrizes e questões norteadoras problematizaram o caminho metodológico da pesquisa.

Quadro 1: Diretrizes para análise da abordagem dos Stakeholders (AS).

\begin{tabular}{|l|l|}
\hline DIRETRIZES & QUESTÕES NORTEADORAS \\
\hline Identificar a principal finalidade da análise & Qual o problema a ser abordado? \\
\hline $\begin{array}{l}\text { Buscar compreender o sistema, suas interações e inter- } \\
\text { relações }\end{array}$ & Quais os objetivos e resultados esperados? \\
\hline Identificar os principais Stakehoders & Quais os critérios de escolha destes agentes \\
\hline $\begin{array}{l}\text { Investigar os interesses, circunstâncias e características } \\
\text { dos Stakeholders }\end{array}$ & Observar quem faz uso e a gestão do recurso \\
\hline $\begin{array}{l}\text { Identificar o contexto e interações entre os Stakeholders } \\
\text { no processo de gestão }\end{array}$ & $\begin{array}{l}\text { Observar questões-chave ou informações que permeiam os } \\
\text { diversos agentes }\end{array}$ \\
\hline $\begin{array}{l}\text { Observar se há conflitos de interesse na gestão dos } \\
\text { recursos }\end{array}$ & $\begin{array}{l}\text { Funciona mais como um apoio, devendo ser auxiliado, se } \\
\text { necessário por outras ferramentas }\end{array}$ \\
\hline
\end{tabular}

Fonte: Grimble et al. (1995).

Esta matriz subsidiou a escolha dos agentes envolvidos no processo de licenciamento em áreas cársticas, tendo como auxílio a análise documental dos instrumentos normativos, observando os aspectos institucionais, legislativos e jurídicos. Desta forma, foram identificados os seguintes Stakeholders: representante do IBAMA e representante do CECAV.

O roteiro de entrevistas partiu de questões semelhantes para os dois Stakeholders, identificados como agentes do licenciamento ambiental em áreas cársticas. Assim, questionou-se qual o papel destes órgãos, quanto ao licenciamento ambiental no Brasil, considerando as suas respectivas atuações. As questões buscaram compreender os interesses e pontos de conflitos existentes no gerenciamento destas áreas, fazendo uma correlação com os instrumentos de gestão, tendo como foco ainda os entraves e dificuldades apontadas pelos órgãos, considerando o processo de implantação de grandes empreendimentos em áreas cársticas.

Por se tratar de uma pesquisa qualitativa, as entrevistas foram analisadas em uma perspectiva interpretativa. Utilizou-se os pressupostos de Patton (2002), uma vez que "as entrevistas devem ser vistas como citações que devem ser interpretadas". A interpretação das entrevistas foi feita, de forma comparativa, ao que está preconizado nos instrumentos do licenciamento ambiental em áreas cársticas no Brasil.

\section{RESULTADOS E DISCUSSÃO}

O território brasileiro é composto por extensas áreas propícias à ocorrência de ambiente cárstico. Mesmo com este cenário ainda incipiente em relação às áreas prospectadas, o Brasil é considerado um dos grandes representantes de paisagem cárstica mundial, conferindo "ao país um valioso Patrimônio Espeleológico" (JANSEN et al., 2012). No entanto, Piló et al. (2011) estimam que apenas 5\% das cavidades brasileiras sejam conhecidas, uma vez que, segundo os dados do CECAV: 
Até o momento, foram identificadas pouco mais de dezessete ${ }^{1}$ mil cavernas, dessas apenas $10 \%$ são validadas, outros $10 \%$ ou não dispõem de dados referentes à localização geoespacial ou apresentam informações errôneas. Em geral a coleta e sistematização desses dados são precárias.

O Brasil disciplinou o uso territorial em áreas cársticas a partir de uma série de instrumentos normativos, destacando as normas editadas pelo Ministério do Meio Ambiente - MMA, do IBAMA e do ICMBio/CECAV. Assim, foram estes instrumentos, aportados pela matriz de Griblem e Chan (1995), que subsidiaram a identificação dos Stakeholders do licenciamento ambiental em áreas cársticas no Brasil, conforme identificados no quadro 2 .

Quadro 2: Instrumentos Normativos do Licenciamento Ambiental em áreas cársticas, órgãos responsáveis e atribuições segundo as normas brasileiras.

\begin{tabular}{|l|l|l|c|}
\hline INSTRUMENTO & ÓRGÃO & ATRIBUIÇÃO & $\begin{array}{c}\text { STAKEHOLDER } \\
\text { ENVOLVIDO }\end{array}$ \\
\hline $\begin{array}{l}\text { Resolução № } \\
005 / 1987\end{array}$ & CONAMA & $\begin{array}{l}\text { Exigência EIA/RIMA para que ocorram autorizações ou licenças } \\
\text { ambientais, em virtude da construção/implantação de } \\
\text { empreendimentos em áreas cársticas. }\end{array}$ & $\begin{array}{c}\text { IBAMA } \\
\text { CECAV }\end{array}$ \\
\hline $\begin{array}{l}\text { Resolução № } \\
237 / 1997\end{array}$ & CONAMA & Diretrizes para elaboração do EIA/RIMA. & IBAMA \\
\hline $\begin{array}{l}\text { Decreto Federal N } \\
6.640 / 2008\end{array}$ & $\begin{array}{l}\text { Governo Federal } \\
\text { (Poder } \\
\text { Executivo) }\end{array}$ & $\begin{array}{l}\text { Definição da classificação dos graus de relevância de } \\
\text { cavidades. }\end{array}$ & IBAMA \\
CECAV
\end{tabular}

Como ponto de partida, é importante compreender que estes instrumentos não devem atuar de forma isolada, uma vez que, as suas respectivas aplicabilidades estão sistemicamente interrelacionadas. De forma simples, pode ser inferido que determinado instrumento depende do que está preconizado em outro instrumento, ou seja, há uma interconexão entre estas normas. A aplicabilidade destes instrumentos deve ainda envolver a atuação dos dois Stakeholders, identificados como responsáveis pelo licenciamento ambiental em áreas cársticas no Brasil: IBAMA e CECAV. Assim, a análise dos dados constantes no quadro 2 , permite depreender que, além do conhecimento no que preconizam tais instrumentos é preciso uma ação conjunta entre esses Stakeholders.

A primeira iniciativa para regulamentação do uso do patrimônio espeleológico brasileiro se deu a partir da instituição da Resolução CONAMA 005/87, que foi responsável pela criação do 'Programa Nacional de Proteção ao Patrimônio Espeleológico', esta foi importante também por incorporar o item $3^{\circ}$ que estabelece 'que seja incluída na Resolução CONAMA no 001/1986², a obrigatoriedade de elaboração de EIA/RIMA nos casos de empreendimento potencialmente lesivos ao Patrimônio Espeleológico Nacional'.

Essa obrigatoriedade também incidiu sobre a Constituição Federal Brasileira de 1988 (C.F). A Carta Magna Brasileira é notadamente conhecida como uma constituição ambiental, uma vez que, foi a primeira a trazer de forma explícita um capítulo inteiro destinado à proteção integral do meio ambiente (art. 225). Situação análoga foi a proteção dada às cavidades naturais subterrâneas, uma vez que a C.F. recepcionou o

\footnotetext{
${ }^{1}$ Dados correspondentes a junho de 2018.

${ }^{2}$ Resolução CONAMA alterada pela 009/86 e depois pela 237/97. 
patrimônio espeleológico brasileiro como um 'bem ambiental'. Essa proteção está descrita em pelo menos três artigos: 20, 216 e 225 da C. F..

O CONAMA ao modificar a Resolução 001/86 através da Resolução 237/97, estabeleceu regras e diretrizes para o licenciamento ambiental no Brasil, incluindo as normas a serem adotadas sobre as áreas cársticas. A resolução CONAMA 237/97 foi então responsável por introduzir definições legais para os componentes do patrimônio espeleológico nacional, definindo conceitos para cavidades e tornando obrigatório o estudo ambiental do componente espeleológico para fins de concessão do licenciamento ambiental. Sobre estes instrumentos, foi solicitado aos dois Stakeholders que pudessem explicar o papel dos seus órgãos, frente ao licenciamento de empreendimentos em áreas cársticas no Brasil:

Considerando que eu trabalho apenas no contexto do licenciamento ambiental, entendo que o IBAMA não está atuando de forma geral na gestão de áreas cársticas, mas, na avaliação de impactos e propostas de compensação quando os empreendimentos licenciados possuem impactos sobre áreas cársticas. (...) Atualmente, a atuação do IBAMA (...) em relação às áreas cársticas tem se limitado àquelas que estão na área de influência de algum empreendimento (REPRESENTANTE IBAMA;

Historicamente o CECAV nasceu em 97 na estrutura do IBAMA e até a criação do Instituo Chico Mendes o CECAV tinha uma participação muito direta com o licenciamento ambiental. A gente tentava desenvolver pesquisa, mas basicamente a equipe se dedicava ao licenciamento ambiental, visto que todo licenciamento do país passava pelo IBAMA das áreas cársticas, digamos que envolvia o impacto ao patrimônio espeleológico especificamente. Com a criação do Chico Mendes, dentro das competências ele atua somente nas unidades de conservação federal e sua zona de amortecimento. (...) Assim, sendo, o IBAMA e os órgãos estaduais é que tratam e atuam diretamente com o licenciamento ambiental (REPRESENTANTE CECAV).

Com base no que informaram os Stakeholders, acerca da atuação de seus órgãos, considerando o que é preconizado nas resoluções CONAMA 005/87 e 237/97 (CONAMA, 1997), destaca-se que o representante do IBAMA reconhece que o principal papel do órgão é a concessão da licença ambiental, o que está de acordo, já que

O IBAMA fará o licenciamento de que trata este artigo após considerar o exame técnico procedido pelos órgãos ambientais dos Estados e Municípios em que se localizar a atividade ou empreendimento, bem como, quando couber, o parecer dos demais órgãos competentes da União, dos Estados, do Distrito Federal e dos Municípios, envolvidos no procedimento de licenciamento.

Já o representante do CECAV também identificou o seu papel no licenciamento ambiental de empreendimentos em áreas cársticas, qual seja: fornecer estudos técnicos e colaborar sistemicamente frente ao licenciamento ambiental destas áreas. Neste sentido, questionou-se ainda como os representantes avaliam a participação dos demais órgãos governamentais que compõem a gestão de áreas cársticas no Brasil. Os Stakeholders entendem que '(...) após a criação do ICMBio e saída do CECAV do IBAMA, a gestão ficou

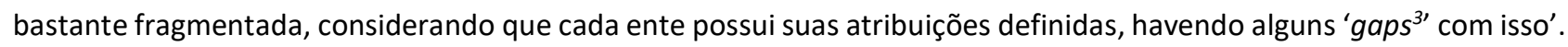

Até onde os que acompanho e o que passa por nós especificamente, eles têm uma atuação dentro das suas competências. Não tenho visto nenhum problema específico. A gente promoveu dentro desse processo de contribuir tecnicamente e ajudar os órgãos licenciadores, nós fizemos quatro cursos de espeleologia e licenciamento ambiental, cada curso desse com cerca cem horas, são dois dias de campo aonde todos os estados

\footnotetext{
${ }^{3}$ Termo em inglês que significa um distanciamento; afastamento, separação, uma lacuna ou um vácuo. GAPS é uma palavra muito usada, e que possui diversos significados, depende onde é empregada.
} 
participaram, tivemos participação de órgãos licenciadores de todos os estados. Todos os órgãos licenciadores tiveram seus técnicos capacitados (...). Foram mais de 200 técnicos capacitados no país inteiro. Para que o órgão começasse a ser capacitado, desde 2011 esse número tem aumentado. (...) O Centro sempre se mantém a disposição para ajudar tecnicamente (REPRESENTANTE CECAV).

A análise destas questões permite inferir que há pontos divergentes neste tópico. Enquanto o representante do IBAMA aponta para uma fragmentação da atuação dos entes do licenciamento, o representante do CECAV, por outro lado, não apontou nenhum problema de incongruência das competências dos demais órgãos na gestão das áreas cársticas, especialmente no que tange ao licenciamento, já que para o representante do órgão, 'No licenciamento a gente dá subsídios, nós desenvolvemos pesquisa muito mais agora do que antes, já que agora a gente não tem a tarefa direta do licenciamento ambiental', afirma Representante CECAV.

O que fica notadamente claro é que, apesar de ter competências definidas, quanto ao licenciamento ambiental, os dois Stakeholders apresentam visões diferentes quanto à atuação de seus órgãos. Para o representante do IBAMA a atuação dos órgãos está muito fragmentada, condição contrária ao que se pretende com uma gestão ambiental sistêmica, sobretudo, em ambientes complexos, como as áreas cársticas. A este respeito, Aragón (2007) se insere na discussão explicitando que a gestão de sistemas ambientais deve ser encarada como sendo:

(...) uma atividade política voltada à formulação de princípios e diretrizes, á estruturação de sistemas gerenciais e a tomada de decisões tem por objetivo final prover, de forma coordenada, o inventario, uso, controle, proteção e conservação de um ambiente visando a atingir o objetivo estratégico do desenvolvimento sustentável.

O entendimento sobre uma gestão de recursos naturais integrada insere em uma necessidade de reconhecer o ambiente em uma perspectiva sistêmica, como fez Vasconcellos (2013), já que para a autora os sistemas ambientais devem ser vistos como "um conjunto de elementos, no qual não se evidenciam as interações ou inter-relações entre as partes" (VASCONCELLOS, 2013). Tal premissa leva, então, à concepção da necessidade de ações integradas em torno dos sistemas ambientais.

A edição do Decreto Federal no 6.640/2008 gera muitas controvérsias e críticas da comunidade espeleológica no Brasil até hoje, isto por que as cavidades retrocederam no que tange ao 'Status' de um bem ambiental com proteção integral, conforme a C. F.. Com o que foi disposto no referido decreto, as cavernas passaram a ser entendidas como um bem passível de compensação ambiental econômica. Isto por que ao estabelecer graus de relevância, algumas cavernas que forem identificadas de baixo grau de relevância poderão ser suprimidas no momento de instalação de um empreendimento, por exemplo.

A sociobiodiversidade associada ao ambiente cárstico sofreu e sofre ameaças diante do Decreto Federal no6.640/2008, como defendeu Lopes (2009), ao empreender que: “(...) é pouco provável que tais cavidades consigam ser graduadas de forma adequada num curto espaço de tempo, conforme determina a norma, correndo o risco de serem lesados patrimônios e dados inéditos, bem como extintos organismos". Acerca deste decreto os Stakeholders entendem que:

(...) A gente atua pelo decreto 6640 na definição das outras formas de compensação conforme está no art. 4ำ do decreto, ou seja, toda vez que o empreendimento não tiver duas cavernas para cada uma impactada para que ele conserve a título de cavidade 
testemunho na área do empreendimento ele deve negociar com o Chico Mendes outras formas de compensação. Essas outras formas são regidas na IN 02/2009 do Chico Mendes. Ele atua enquanto o comitê gestor do licenciamento. Então isso muda completamente a nossa competência, passando atuar de forma mais macro, de uma forma com a equipe que se tem, contribuir para a gestão do patrimônio espeleológico como um todo (REPRESENTANTE CECAV);

Nos empreendimentos onde existem impactos sobre o patrimônio espeleológico, o IBAMA exige os estudos e aplica a metodologia para classificação e grau de relevância previstos no Decreto Federal 6640/2008 e a IN/MMA/2009, em seguida é feita a análise da proposta de compensação das cavidades impactadas. O empreendedor apresenta os estudos necessários para a classificação do grau de relevância. O IBAMA analisa tais estudos, podendo pedir eventuais complementações, em seguida realiza a classificação das cavidades. A partir daí, o empreendedor deve apresentar a proposta de compensação para avaliação do Ibama (REPRESENTANTE IBAMA).

Os Stakeholders citam o papel do Decreto, no entanto, não o considera lesivo, quando se trata da conservação do ambiente cárstico. Concepção contrária ao que analisou Lopes (2009) e Figueiredo et al. (2010). Um dos maiores impasses trazidos pelo decreto é a subjetividade acerca dos critérios para classificação de cavernas. Miranda (2009), ao evidenciar essa subjetividade explica que

(...) há evidente redução ou retrogradação do nível de proteção que, até então revestia o patrimônio espeleológico brasileiro, o que também é vedado, pois a doutrina constitucionalista censura a aniquilação de conquistas protetivas, de forma que a tutela normativa deve se operar de modo progressivo no âmbito das relações jurídicas, a fim de não retroceder jamais a um nível de proteção inferior àquele já alcançado.

Ao analisar a proposição de Miranda (2009), percebe-se que houve uma mudança nas relações jurídicas com o patrimônio espeleológico. As cavernas passaram a ser classificadas como relevantes ou irrelevantes. Estabelecendo, uma caracterização das mesmas de forma dicotômica, como propõe Trajano (2009), "Logicamente, pode-se provar a existência de um atributo, mas não sua ausência. Ou seja, ausência de evidência não é evidência da ausência. Esta é a base da própria ciência, estruturados sobre os fundamentos lógicos".

Todo o imbróglio em torno do Decreto Federal N 6.640/2008 levou o MMA a regulamentar a sua aplicabilidade, através da IN/MMA 002/2009, que entre as principais atribuições tratou de estabelecer a metodologia para classificação das cavernas em graus de relevância. Sobre a IN/MMA 002/09, os dois Stakeholders afirmam conhecê-la e aplicá-la, no entanto, não correlacionam à existência de nenhuma problemática, quanto à sua aplicabilidade. Contudo, aponta Ferraz (2014), a IN/MMA 002/2009

(...) não foi desenhada respeitando a análise em conjunto de atributos definidos pelo caput do artigo $2^{\circ}$ do Decreto (...) que apesar de definir que há de se avaliar uma série de atributos para avaliação de cavidades, permite que haja apenas um atributo entre onze possibilidades para a determinação de cavidade de máxima relevância.

A priori, cabe citar que os mesmos conceitos de cavidade natural subterrânea da IN/MMA 002/2009 são os mesmos descritos no Decreto Federal no 6.640/2008. Por outro lado, cabe destacar que o método de classificação não prevê cavidades irrelevantes ou sem relevância, portanto, toda cavidade natural subterrânea possui relevância. Ferraz (2014) se posiciona acerca desse critério de relevância de cavernas apontando que tal classificação só tem sentido quando ocorre o licenciamento ambiental dos empreendimentos, pois segundo Ferraz (2014) 
A classificação das cavidades serve como instrumento técnico-legal para a avaliação dos impactos ambientais sobre esses recursos ambientais, não fazendo sentido a exigência da avaliação de relevância da cavidade por sua mera existência. Caso houvesse a necessidade de se classificar todas as cavidades existentes no Brasil, caberia ao Poder Público realizar ou exigir de que todos os proprietários de imóveis detentores de cavidades devessem realizar tais estudos.

Assim, para fins de avaliação dos impactos ambientais, a classificação de cavidades em graus de relevância deve ser somente exigível às atividades passíveis de impactos ambientais significativos ao patrimônio espeleológico e suas áreas de influência. Não havendo necessidade de classificação quando a cavidade não sofrer nenhuma ameaça ou impacto ao seu sistema.

Um dos fundamentos jurídicos mais fortes que envolvem o licenciamento ambiental é a necessidade de mitigar e compensar danos aos recursos naturais causados pelas ações antrópicas, sobretudo, a construção ou ampliação de grandes empreendimentos. Portanto, em se tratando de ecossistemas extremamente frágeis, como as áreas cársticas, as suas formas de compensação representam um elemento chave. Para compreender o entendimento dos Stakeholders, quanto às formas de compensação de impacto em áreas cársticas, observando-se a IN/ICMBio 030/12, eles entendem que

A gente passou a desenvolver pesquisas voltadas às diretrizes e orientações para ao licenciamento ambiental. Hoje todos os nossos projetos eles visam a atender ao Programa Nacional de Conservação do Patrimônio Espeleológico. Todos os nossos projetos eles estão dispostos a atender às séries advindas do Programa Nacional, ele é o que nos norteia. Esses projetos visam melhorar a conservação do patrimônio espeleológico (REPRESENTANTE CECAV).

O empreendedor apresenta os estudos necessários para a classificação do grau de relevância. O IBAMA analisa tais estudos, podendo pedir eventuais complementações, em seguida realiza a classificação das cavidades. A partir daí, o empreendedor deve apresentar a proposta de compensação para avaliação do IBAMA (REPRESENTANTE IBAMA).

As inferências dos Stakeholders revelam que estes possuem conhecimento sobre a importância da compensação ambiental em áreas cársticas, especialmente o representante do CECAV, que considera que o Programa Nacional de Conservação do Patrimônio Espeleológico - PNCPE é, atualmente, o principal instrumento de conservação/compensação do uso de áreas cársticas. O representante do IBAMA, deixa claro que o órgão avalia as formas de compensação apresentadas pelo empreendedor.

Por outro lado, não mencionaram um problema ainda tácito pela IN/MMA 030/12 que é o aspecto espacial da compensação, ocasionando divergência na aplicação deste dispositivo pelos órgãos ambientais responsáveis e dificuldades de operacionalização por parte do empreendedor. Isso porque, de acordo com o entendimento de Milaré (2004):

(...) ao contrário do que ocorre, por exemplo, na legislação urbanística, as normas ambientais são, por vezes, muito genéricas, não estabelecendo, via de regra, padrões específicos e determinados para esta ou aquela atividade. Nestes casos, o vazio da norma legal é geralmente preenchido por exame técnico apropriado, ou seja, pela chamada discricionariedade técnica, deferida à autoridade.

O proposto por Milaré (2004) faz-se do mesmo entendimento de que o licenciamento ambiental em áreas cársticas, bem como suas formas de compensação, ainda carecem de um exame mais detalhado e minucioso, uma vez que os instrumentos ainda apresentam vazios e divergências, sobretudo, nos aspectos de classificação das cavidades e nos critérios metodológicos para análise do impacto e medidas mitigadoras. 
Apesar do expressivo aparato legal e institucional, ainda não se pode garantir a conservação deste importante sistema ambiental.

A aplicabilidade destes instrumentos só atinge o grau de eficiência e eficácia, caso os Stakeholders exerçam o seu papel, no âmbito de suas competências, começando pelo entendimento dos instrumentos, reconhecendo a importância do licenciamento ambiental, para garantir a conservação dos recursos naturais e a necessidade de uma atuação conjunta e sistêmica.

\section{CONCLUSÕES}

Considerar o licenciamento ambiental como um instrumento de conservação ganha ainda mais importância quando se reconhece a fragilidade de alguns ecossistemas. Neste sentido, as áreas cársticas devem receber um tratamento peculiar quanto à aplicabilidade deste instrumento, no que tange às formas de mitigação e compensação ambiental. Ao considerar o ambiente cárstico um sistema, as ações advindas de seu uso também devem ser sistêmicas. Diante da obrigatoriedade em licenciar obras e empreendimentos em áreas cársticas, cabe aos órgãos ambientais observar o que preconizam os instrumentos de gestão que regulamentam o ato, destacando-se a necessidade de aplicar as normas de regulamentação da compensação ambiental.

O licenciamento ambiental em áreas cársticas deve ser visto como um processo de articulação das ações dos diferentes agentes que compõem a estrutura dos órgãos licenciadores e, portanto, deve haver interação de forma sistêmica, baseando-se em princípios e diretrizes previamente estabelecidos. Portanto, esta pesquisa identificou a visão dos Stakeholders do licenciamento ambiental em áreas cársticas, apontando o entendimento destes acerca das principais normas ambientais e compreendendo possíveis entraves do/no processo. Os Stakeholders entrevistados não apontaram grandes dificuldades quanto à aplicabilidade destas normas, no entanto, não houve apontamentos tácitos de uma gestão sistêmica entre estes órgãos.

Por outro lado, alguns trabalhos que envolvem a análises dos instrumentos do licenciamento ambiental, citados nesta pesquisa, apontaram entraves quanto à aplicabilidade e eficácia destas normas. A atuação sistêmica e integrada, deve, portanto, ser condição basilar para a gestão e uso ambientalmente responsável das áraes cársticas. Assim, o licenciamento ambiental exerce o papel de regular atividades antrópicas nestas áreas. A título de algumas considerações esta pesquisa salienta que, enquanto atuação sistêmica, a ação dos Stakeholders ainda precisa evoluir.

\section{REFERÊNCIAS}

ARAGÓN, L. E.. População e Meio Ambiente na Pan-

Amazônica: avanços e desafio de pesquisa. Belém: UFPA, 2007.

BRASIL. Constituição da República Federativa do Brasil. Brasília: Senado Federal, 1988.

BRASIL. Decreto Federal n.6640 de 7 de novembro de 2008. Dá nova redação aos arts. 1으, 2으, 3으, 4으 e 5으 e acrescenta os arts. 5-A e 5-B ao Decreto n.99556, de 10 de outubro de 1990, que dispõe sobre a proteção das cavidades naturais subterrâneas existentes no território nacional. Brasília: DOU, 2008.

BURSZTYN, M. A.; BURSZTYN, M.. Fundamentos de Política e Gestão Ambiental: caminhos para a sustentabilidade. Rio de Janeiro: Garamond, 2012.

CAMPBELL, A.. Stakeholders: the case in Favour. Long Range Planning, v.30, n.4, p.446-449, 1997. 
CAVALCANTI, L. F.; COSTA NETO, J. F.; RIBEIRO, A. A.; LIMA, M. F.; MEDEIROS, R. C.; MEGUERDITCHIAN, I.. A situação atual do patrimônio espeleológico brasileiro: dados preliminares. In: RASTEIRO, M. A.; MORATO, L.. CONGRESSO BRASILEIRO DE ESPELEOLOGIA, 32, Barreiras. Anais. Campinas: SBE, 2013. p.231-238.

CAVALCANTI, L. F.; LIMA, M. F.; MEDEIROS, R. C. S.; EGUERDITCHIAN, I.. Plano de ação nacional para a conservação do patrimônio espeleológico nas áreas cársticas da Bacia do Rio São Francisco. Brasília: ICMBio, 2012.

CONAMA. Conselho Nacional de Meio Ambiente. Resolução n.001 de 23 de janeiro de 1986. Brasília: MMA, 1986.

CONAMA. Conselho Nacional de Meio Ambiente. Resolução n.005 de 06 de agosto de 1987. Brasília: MMA, 1987.

CONAMA. Conselho Nacional de Meio Ambiente. Resolução n.237, de 19 de dezembro de 1997. Brasília: MMA, 1997.

CONAMA. Conselho Nacional de Meio Ambiente. Resolução n.347 de 10 de setembro de 2004. Brasília: MMA, 2004.

CORRÊA, S. A.; SILVA, F. C.. O processo de descentralização da gestão ambiental a partir da Teoria Institucionalista: um novo olhar?. In: ALMEIDA, O.; FIGUEIREDO, S. L.; TRINDADE JÚNIOR, S.. Desenvolvimento e Sustentabilidade. Belém: NAEA, 2012. p.12-28.

FERRAZ, P. C.. Cavernas: conservação ou preservação. Jus navegandi, v.1, n.12, p.12-23, 2014.

FIGUEIREDO, L. A. V.; RASTEIRO, M. A.; RODRIGUES, P. C.. Legislação para proteção do patrimônio espeleológico brasileiro: mudanças, conflitos e o papel da sociedade civil. Espeleo-tema, v.21, n.1, p.49-65, 2010.

FREEMAN, R. E.. Strategic Management: a Stakeholder Approach. Boston: Pitman, 1984.

GRIMBLE, R.; CHAN, M. K.. Stakeholder analysis for natural resource management in developing countries: some practical guidelines for making management more participatory and effective. Natural Resource Forum, v.1, n.19, p.113-124, 1995.

JANSEN, D. C.; CAVALCANTI, L. F.; LAMBLÉM, H. S.. Mapa de Potencialidade de Ocorrência de Cavernas no Brasil, na Escala 1:2.500.000. Revista Brasileira de Espeleologia, v.2, n.1, p.23-45, 2012.

LOPES, M. M.. A proteção das cavidades naturais subterrâneas e os problemas trazidos pelo decreto 6.640/08. In: CONGRESSO INTERNACIONAL DE DIREITO AMBIENTAL, 13. Anais. São Paulo: IDPV, 2009.

MILARÉ, E.. Direito do ambiente. São Paulo: Revista dos Tribunais, 2004.

MIRANDA, M. P. S.. Decreto 6.640/2008: patrimônio espeleológico brasileiro sob ameaça. Conexão Subterrânea. Redespeleo Brasil, v.1, n.73, p.23-45, 2009.

PATTON, M. Q.. Qualitative research and evaluation methods. Sacramento: Sage, 2002.

PILÓ, L. B.; AULER, A.. Introdução à Espeleologia. In: CURSO DE ESPELEOLOGIA E LICENCIAMENTO AMBIENTAL, 3. Anais. Brasília: ICMBio, 2011. p.7-23.

RIBAS, M. R.; CARVALHO, L. C.. Cavidade natural subterrânea: natureza jurídica. Interações, Campo Grande, v.10, n.1, p.83-93, 2009.

ROWLEY, T.. Moving beyond dyadic ties: a network theory of stakeholder influences. Academy of Management Review, v.1, n.22, p. 887-910, 1998.

TRAJANO, E.. Relevância de sistemas subterrâneos: método é essencial. Conexão Subterrânea. São Paulo: Redespeleo Brasil, v.1, n.73, p.45-67, 2009.

VASCONCELLOS, M. J. E.. Pensamento Sistêmico: o novo paradigma da ciência. 10 ed. Campinas: Papirus, 2013.

A CBPC - Companhia Brasileira de Produção Científica (CNPJ: 11.221.422/0001-03) detém os direitos materiais desta publicação. Os direitos referem-se à publicação do trabalho em qualquer parte do mundo, incluindo os direitos às renovações, expansões e disseminações da contribuição, bem como outros direitos subsidiários. Todos os trabalhos publicados eletronicamente poderão posteriormente ser publicados em coletâneas impressas sob coordenação da Sustenere Publishing, da Companhia Brasileira de Produção Científica e seus parceiros autorizados. Os (as) autores (as) preservam os direitos autorais, mas não têm permissão para a publicação da contribuição em outro meio, impresso ou digital, em português ou em tradução. 